
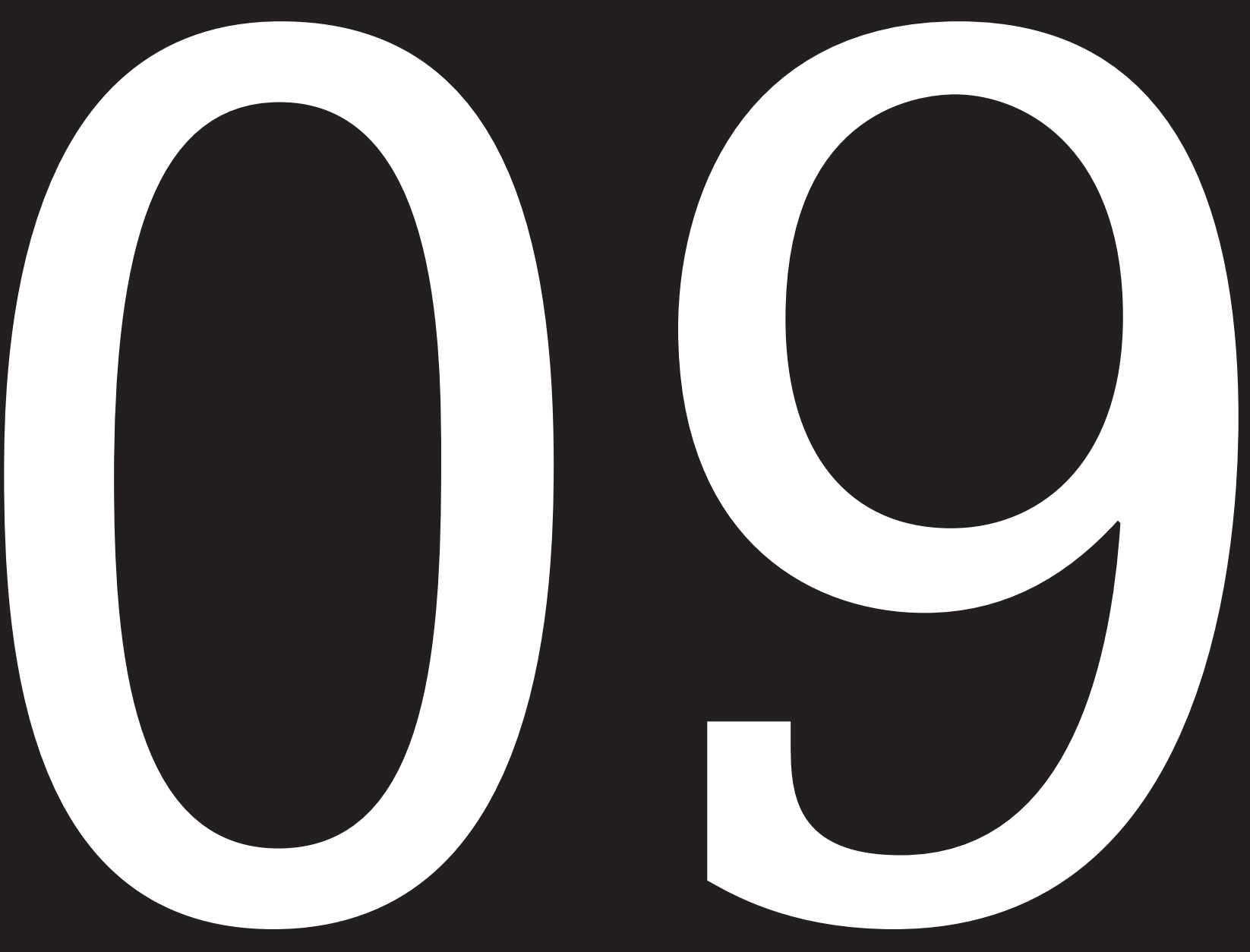

DOI: https://doi.org/10.14483/2422278X.18562 


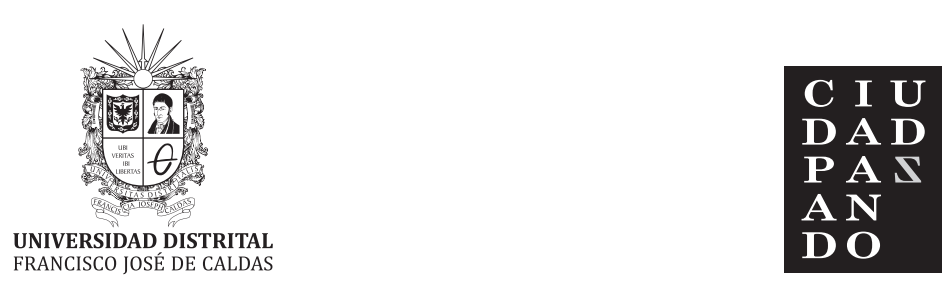

ISSN impreso: 2011-5253

ISSN en línea: 2422-278X

\section{RESEÑA \\ Paisajes Inadvertidos: Miradas de la Guerra en Bogotá}

\section{Sara Gineth Guzmán Grandas ${ }^{1}$ \\ Colombia}

Para citar: Guzmán, S. (2021). Paisajes Inadvertidos: Miradas de la Guerra en Bogotá. Ciudad Paz-ando, 14(2), 118-121. doi: https://doi.org/10.14483/2422278X.18562

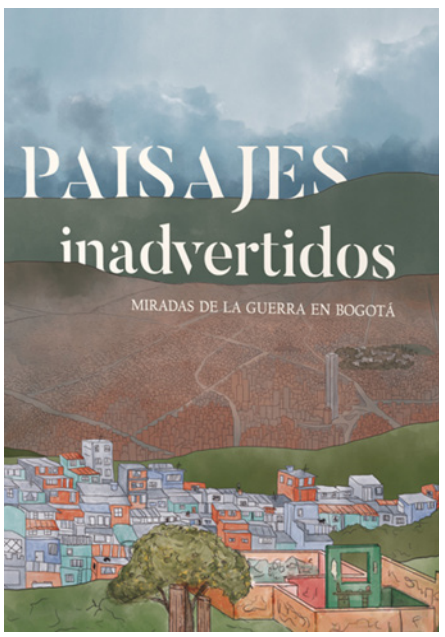

Centro de Memoria, Paz y Reconciliación. (2019). Paisajes inadvertidos.

Miradas de la guerra en Bogotá. Alcaldía Mayor de Bogotá

La historia de Colombia sin duda está marcada por la violencia armada: las tomas guerrilleras, masacres, secuestros, desplazamientos, extorsiones y pescas milagrosas, entre otras tantas más, son fenómenos que según diversas investigaciones realizadas por ONG's, Organismos gu- bernamentales, universidades y grupos de investigación, han afectado principalmente las zonas rurales, y con ello a la población campesina del país. No obstante, los denominados carros bomba, asesinatos y el asentamiento en las ciudades de las personas desplazadas de las zonas ru-

1 Trabajadora social de la Universidad de La Salle. Coordinadora académica de la Cátedra Democracia y Ciudadanía y profesional administrativo del Instituto para la Pedagogía, la Pazy el Conflicto Urbano de la Universidad Distrital Francisco José de Caldas - IPAZUD. Correo: sguzmangrandas@ gmail.com ORCID: https://orcid.org/0000-0003-2323-8241 
rales, permiten observar que la violencia impacta a todos los habitantes y territorios del país, y que las ciudades de Colombia también han sido blanco de diferentes hechos violentos a causa del conflicto armado.

En este escenario, el Centro de Memoria, Paz y Reconciliación de la Alcaldía Mayor de Bogotá - CMPR, publicó el libro "Paisajes inadvertidos. Miradas de la guerra en Bogotá" en el cual se exponen cuatro historias desarrolladas en la capital del país, con el propósito de analizar los impactos del conflicto armado en la ciudad, junto con las transformaciones que ha vivido la urbe a causa de la guerra y cómo estas historias e impactos se relacionan con imágenes y paisajes cotidianos en la ciudad.

El libro inicia con el prólogo escrito por Arturo Charria, coordinador del CMPR, que explica cómo en los inicios del Siglo XX la escuela paisajista del país enmarcaba las obras que engrandecen el campo y la naturaleza como parte de la estética artística nacional. Ejemplos de ello, son la gran cantidad de obras pictóricas que ilustran los jardines y caminos iluminados que llevaron a muchos de los artistas plásticos de la capital a recrear las pintorescas casas de la sabana de Bogotá. Dentro de ellas no se mostraban los conflictos ni las carencias que se podían presentar dentro de ellas, pero sí se evidenciaban los valores nacionales.

El objetivo de la publicación, menciona el prólogo, es reconocer que la guerra marcó la vida de muchas personas que hoy habitan la ciudad a través de los que se denominan como paisajes inadvertidos; una suerte de antítesis de los lugares emblemáticos de la ciudad. Lo anterior, en tanto comprender otros paisajes implica observar las dinámicas de la violencia en la ciudad más allá de ciertas situaciones emblemáticas de Bogotá, tales como la toma del Palacio de Justicia y el atentado al Club el Nogal.

De la misma manera, a partir de las categorías de verdad, historia, archivo, trauma y tiempo, se incluye el gran campo de estudio de la memoria como parte fundamental del análisis que presenta el libro. Lo anterior, debido a que los mencionados conceptos permiten al recopilador o narrador tejer un hilo conductor entre las historias y memorias en pro de observar las huellas que deja un hecho violento en una persona.

"En Bogotá no se vivió la guerra", es la frase con la que inicia el análisis de lo que significa el conflicto armado para los habitantes de la ciudad. Cuando la gente repite mucho algo, esto termina por parecer verdad. Esa es la primera conclusión. En este sentido, se hace un llamado a entender que la guerra se debe abordar partiendo de tres categorías:

- Espectáculo. El hecho de que cada año se vuelve a contar algún suceso violento a través de imágenes con el objetivo de que este se emplace en la memoria colectiva de la ciudadanía.

- Cotidianidad. Se relaciona con lo invisible, ya que está marcada por la naturalización que realiza la población sobre ciertos comportamientos. Algunos se vinculan con la guerra, otros con regionalismos y finalmente otros pasan desapercibidos, debido a que no se reconocen las diferencias existentes entre la violencia armada en el campo y la ciudad.

- Olvido. Esta categoría se relaciona con la memoria y los intereses particulares de las hegemonías nacionales y capitalinas por borrar el rastro de la guerra en la ciudad.

Con los conceptos anteriormente mencionados claros, el libro anuncia que está dividido en tres partes principales en las cuales se narran cuatro historias de vida: $i$. recorridos de la memoria, ii. transformaciones del paisaje y iii. mapas de la deriva. La primera parte inicia con la historia denominada En Sumapaz | Al sur, en la cual, luego de describir los paisajes que se pueden observar desde el centro de la ciudad hasta la localidad en cuestión, enfatizando en características fundamentales como son los frailejones típicos de los páramos, se realiza un recorrido histórico sobre la estética de las viviendas del lugar en el siglo XIX y su transformación en el XX, cuando los habitantes de la localidad lograron acceder a las escrituras de los predios, por lo cual se organizaron y pudieron construir las primeras escuelas. Posteriormente, se expone cómo afectó al Sumapaz la violencia que se originó con el asesinato de Jorge Eliecer Gaitán en el año 1948, enfatizando en el fenómeno de despojos de tierras por parte de "Los Fieles", y cómo los habitantes de la localidad se organizaron mediante una alarma para no permitir que le prendieran fuego a las casas.

Lo anterior se da como preámbulo para conocer la historia de Leopoldo, quien habita del lugar luego del nacimiento su primer hijo. Algo que coincidió con el tiempo cuando las FARC decidieron cambiar la estructura militar y organizativa para la toma del poder y en consecuencia estar cerca de la ciudad. Por ello, se menciona, que en 1990 el grupo guerrillero se ubicó en las faldas de la cordillera y a medida que tomó fuerza se podían observar a los secuestrados caminar escoltados por niños y jóvenes del Sumapaz que habían sido reclutados de manera forzosa.

La segunda parte de esa primera historia, denominada En Sumapaz | Avispas furiosas, cuenta cómo la hija de Leopoldo fue reclutada por la guerrilla. Cuando Sandra Paola cumplió trece años realizaba labores de crianza mientras sus padres buscaban nuevas formas de ingresos, aunque sabía muy bien que la guerrilla iba de casa en casa eligiendo niños para reclutar, cosa que terminó por sucederle a ella misma el 04 de diciembre del año 2001. Posteriormente, después de cuatro meses de que la guerrilla se llevará a Sandra y luego de quedar atrapados en medio de un combate entre el Ejército Nacional y el grupo guerrillero, Devier, hijo de Leopoldo, murió tras ser alcanzado por una bala en el costado de su cuerpo. 
En Sumapaz| Después de la guerra, la última parte de esta primera historia, inicia relatando los hechos que ocurrieron después de la muerte de Devier. Leopoldo y su familia se trasladaron a un lugar más cercano a la ciudad, aunque aún dentro del territorio de la localidad de Sumapaz, tratando de escapar de la violencia. Se narra cómo todos los días acudían a la Fiscalía General de la Nación para preguntar por Sandra Paola, pero que nunca tuvieron respuesta. Asimismo, en el año 2016 cuando comenzaba el desarme de las FARC, visitaron los campamentos en donde se encontraban los militantes del grupo armado ilegal, pero tampoco hallaron indicios de su paradero. A pesar de lo sucedido, Leopoldo aún sigue recogiendo los frutos que da esta tierra fértil y sigue viendo crecer a su familia.

La segunda historia titulada En las plazas | Puro pueblo, cuenta cómo Nydia, quien creció en el barrio la Cruces en Bogotá y para el año 1984 ya era la mano derecha de Augusto Lara, miembro del comando político del Movimiento 19 de Abril - M19, resulta muerta a mediados de los años 80's. Su cuerpo fue hallado a las orillas de la carretera vía al Llano tras la muerte de Lara Sánchez y la desaparición de varios de sus compañeros. En las plazas | Sobre heroínas y tumbas, inicia con el relato de la familia de Nydia en su cruzada por encontrarla, enfatizando en el tránsito de su hijo Erick hasta enterarse, luego de un informe de la procuraduría, que estaba enterrada en el cementerio de Guayabetal cerca de la ciudad de Villavicencio.

En la plaza| Un vestido y tres entierros, relata la desaparición de Nydia desde el punto de vista de Yanette y su viacrucis cuando se dirigió a la Procuraduría para denunciar la desaparición de su hermana. Además, se relata cómo fueron los tres entierros de Nydia (primero cuando la asesinaron, después cuando la encontraron sus familiares y finalmente cuando por cuestiones monetarias debieron cremar su cuerpo para depositar las cenizas en un lugar menos costoso) y el hostigamiento que vivió ella y su familia después de encontrar el cuerpo de su hermana, por lo cual decidieron irse a vivir a Alemania. Ya en Europa, levantaron la fundación Nydia Erika Bautista en Suiza, con el objetivo de visibilizar el fenómeno de la desaparición forzada en el mundo.

A renglón seguido, Sobre la quinta | Los herejes, cuenta la historia de Mario Calderón y Elsa Alvarado, investigadores del Centro de Investigación y Educación Popular - CINEP, asesinados por uno de los bloques de las Autodefensas Unidas de Colombia (AUC) frente a la Universidad de la Salle en Bogotá. Sobre la quinta | Rompecabezas, continúa con el relato de Iván, quién a raíz de las preguntas acerca de la muerte de sus padres terminó por estudiar Sociología, ser pasante en el mismo Centro de Investigación y retornar a una casa, ubicada en el Sumapaz, donde Mario y Elsa planeaban pasar su vejez. Cerrando esta historia, Sobre la quinta| Vendrá la utopía, cuenta cómo de las AUC cuando se reunieron para establecer cómo iban a eliminar a las personas que hablaban de paz en la ciudad. Para ello, construyeron una lista con los datos de sesenta personas, entre los que se encontraban Eduardo Umaña y los investigadores del CINEP Elsa y Mario.

La cuarta historia se denomina Entre la ciudad y la montaña | La oruga y la mariposa, apartado que relata cómo Luis fue secuestrado por hombres pertenecientes a las FARC que interceptaron su vehículo un 28 de junio, luego de salir de su oficina ubicada cerca al puente de la carrera 30 con calle 80 en Bogotá. Entre la ciudad y la montaña| Sombras y palomas blancas, inicia con Oriana, hija de Luis, quien comenzó hacer campaña por el Sí en el Plebiscito sobre los Acuerdos de Paz de Colombia de 2016. El libro ahonda en las sensaciones de la familia víctima de secuestro, cuando el 2 de octubre de año 2016 observaba cómo ganaba el No en las urnas del país.

Finalmente, en la tercera parte titulada Entre la ciudad y la montaña | Contamíname, el libro presenta los recuerdos de Luis junto a la montaña, la lluvia y sus secuestradores; particularmente sobre los pensamientos que se suscitaron en una conversación que tuvo con Ernesto, su último cuidador en el cautiverio, cuando realizó una comparación entre los dos. Le impactaron las palabras del guerrillero, pues Luis tenía una vida, una familia y con ello muchas anécdotas por contar, mientras que Ernesto no tenía a nadie, pero con todo debía dar la vida por él si era necesario.

Es de resaltar que este libro aborda, desde algunos casos particulares, las distintas maneras en las que Bogotá ha vivido la violencia armada: los toques de queda, las barreras invisibles o la limpieza social, son ejemplo de ello. Por otra parte, demuestra que en el país no es necesario ser alguien conocido públicamente para resultar sufriendo los hechos de la guerra. El libro propone un análisis y reflexión más allá de los lugares emblemáticos respecto al conflicto armado que como sociedad distinguimos en el imaginario nacional. Es decir, por medio de esta publicación el CMPR visibiliza aquellos lugares que no se conocen, pero que resultan ser significativos para muchas familias que habitan la ciudad, en un intento de que estos paisajes inadvertidos dejen de ser ignorados en el estudio de las memorias de la guerra en el país.

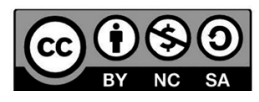

